\title{
Non-state actors and the quest for authority in Arctic governance
}

The modern state, as discussed in Chapter 1 , can be considered a relative newcomer to the cross-border politics of the Arctic region. However, states have featured prominently in the preceding two chapters. We have come to see how advantageous positions earned by/granted to states vis-à-vis other states matter for shaping the rules of the road in Arctic cooperative governance - and ultimately shape outcomes. In this chapter, I seek to broaden the net to explore the positions of key non-state actors involved in Arctic governance, namely indigenous peoples' organisations and science actors.

I do so, however, with two important caveats derived from developments in IR literature. First, I do not consider power in global governance to be a zero-sum game. This would envision power as a capacity or a quantity, rather than a performance facilitated by relations of dominance and deference. In other words, the power exercised by nonstate actors does not come necessarily at the expense of the State and does not result in the 'retreat of the State'. In fact, the influence of nonstate actors may be highly symbiotic with or reliant upon relations to states (Neumann and Sending, 2010). One way of getting at these interactive relations is to consider the question of authority. Authority can be broadly construed as the capacity to secure deference from others in a given setting by wielding successfully whichever forms of capital are highly prized in that particular policy field. Put another way, all actors involved in a policy field are engaged in negotiation over what counts as authority in the first place and, by extension, who is recognised as performing diplomacy authoritatively.

A second caveat relates directly to this idea of authority. Earlier research in global governance tended to posit that different 'kinds' of actors possessed different forms of authority. For example, NGOs or indigenous peoples' organisations would exercise 'moral authority' based on their status as representing affected parties and the original peoples of 
the Arctic, whereas scientists would exercise 'expert authority', and international organisations a 'delegated authority' derived from their membership (Barnett and Duvall, 2004). Instead, we will look at debates over authority more generally to explore the range of performances that can shape outcomes - without positing at the outset that non-state actors engage in global governance in fundamentally different ways than state actors.

The focus on authority allows us to think about the kinds of resources and performances that shore up power relations in Arctic cross-border governance. We can therefore consider the proposition that power relations are malleable and constantly enacted, contested and redefined. Furthermore, authority's common-sense connection to 'knowing what is best' is also helpful in this context. Much of Arctic cooperation has focused around knowledge - be it compilation of knowledge into assessment of the Arctic environment or exchange of policy knowledge across the borders of the North in various people-to-people formats.

The chapter aims to bring contestation over authority into sharp focus by looking at how two non-state actors 'meet the state' directly at high level (SAO, ministerial) within the Arctic Council. We first look at how debates around the 'science-policy interface' manifest themselves more generally. When is discussion of scientific knowledge (or the presence/autonomy of scientists) given weight at the high-political level? Turning to indigenous diplomacy, we analyse and categorise Permanent Participants' diplomatic interventions in the Arctic Council (which is, of course, just one stage upon which the multifaceted politics of indigenous sovereignty is enacted). In the concluding section, I discuss a concept borrowed from science and technology studies that I think serves well to capture the ongoing dynamics around authority in a cross-cutting, regionally based 'umbrella' policy field such as the Arctic. This concept - civic epistemology - is first introduced in the coming section.

\section{Authority in global governance}

Rapid globalisation at the end of the Cold War increased and rendered highly visible the multitude of non-state actors and social movements shaping a growing number of transnational policy fields. In coming to grips with this new quantity and visibility, IR scholars working in global governance first operated with implicit (and sometimes explicit) assumptions that the activities of non-state actors in global governance were fundamentally distinct from the functions of states and were perhaps pushing the State out of global governance (see Neumann and Sending, 2010, for a discussion of this notion). 
As this scholarship of global politics has developed, there is a growing range of studies that suggest an open approach to the question of authority. This recognises the participation of many actors, but remains agnostic as to the kind of politics that they will be pursuing (e.g. one would not assume that NGOs are engaged in a politics of morality, and experts only in a politics of expertise). Sending suggests that a productive way to approach global governance in a conceptual open way is to envision global politics (and its sub-sets) as an 'ongoing competition for the authority to define what is to be governed, how and why' (2015: 4). Actors are conceived as all engaged in the same quest for authority, even if possessing different interests and more and less advantageous starting points. In other words, rather than assuming that scientists exercise 'expert authority' and indigenous peoples gain from 'moral authority' a different question is needed. Why are some communities of actors perceived of as more credible and relevant in a given policy field than other actors?

Empirically, we see that contestation over knowledge is a key aspect of the contemporary politics of securing authority. In Sending's case, he looks at competing policy communities around population control and peacekeeping (2015). Fourcade (2009) looks at the dominance of economists educated at a small handful of institutions in defining how success in 'development' can be achieved and disseminating this globally through multilateral, national and private institutions. Others have examined how economists and foresters have battled it out in shaping how rainforests will matter for global climate mitigation (Wilson Rowe, 2015) or in defining children's rights (Hakli and Kallio, 2014). All of these studies tend to be fairly tightly focused on one thematic policy field and construct a genealogy of that field as their analytical window on authority. A genealogy is a long-lines tracing back of how different communities of knowledge or networks of actors competed to gain the privileged position of defining what matters in a given global governance field.

A genealogy is a tricky method to apply to contemporary Arctic crossborder governance, although it might be possible if one took a highly specific policy area or actor (e.g. Shadian, 2014, 2017 on the Inuit polity) or worked at a high level of abstraction. In its broadest sense, the regionally defined Arctic policy field is an ecosystem of many intersecting policy fields that overlap with local, national and non-Arctic international policy fields (see Introduction for a discussion of this). In other words, if we are considering the Arctic Council to be a policy field (rather than focusing on its institutional aspects), we have to think about how to capture the authority dynamics brought by many different actors with their own histories of political development to a large suite of policy issues, which have their own local, regional and often global genealogies as well. 
Therefore, this chapter explores a systematising 'snapshot' approach, borrowed from science and technology studies, that may be fruitful in bringing problems of Arctic authority to light. In her cross-country comparison of political debates around biotechnology in Germany, the United States and the United Kingdom, Sheila Jasanoff notes persistent differences in national ways of meeting some common questions posed by biotechnology debates, even in relatively similar western states. She asserts that norms of debate, modes of trust, and the roles of and expectations about experts and expertise continue to vary across national borders - and describes this set of attitudes and practices as a 'civic epistemology' (Jasanoff, 2005). These civic epistemology indicators can provide a systematic snapshot view of settled/forgotten, ongoing and upcoming contestations over whose knowledge matters and how it should be presented, thereby providing a good window onto the politics of authority.

Putting debates over the relevance/appropriateness/credibility of knowledge in decision-making settings makes sense in trying to understand authority in an Arctic context, as knowledge has been part of the 'high politics' of the Arctic for centuries. The intertwining of knowledge and science with the pursuit of sovereignty and regional influence has a long history in the Arctic. From the scientific pursuits of early Arctic explorers through to the national emphases on Arctic science in the twentieth century, Arctic state-building has been reliant upon claiming to know the Arctic physical environment via science and through maintaining a physical presence via both military installations and science infrastructure (Bravo and Sörlin, 2002; Bravo, 2005; Shadian, 2009). As one Russian diplomat put it in an interview with the author in October 2011, 'no one knows the Arctic and its challenges like the Arctic states themselves - no one can govern the Arctic better than we can'. And as discussed in Chapter 3, Norway's claim to status in regional hierarchy has been tightly tied to the idea of being at the forefront of knowledge about the High North and the Arctic (MFA, Norway, 2011). Likewise, indigenous peoples' organisations seeking to decolonise relations of power have worked to make space in local, national and international planning and management for the observational and experiential knowledge gathered from close interaction with Arctic ecosystems (traditional knowledge/traditional ecological knowledge) (Huntington, 2000).

As we shall see below, questions of knowledge (whose should count, and who should be heard and how) are, unsurprisingly, actively and explicitly debated at the political level in the Arctic Council, both in terms of science/knowledge actors meeting the State and indigenous sovereignties meeting the State. What do these contours of debate tell us about broader tussles over the effective performance of authority? 


\section{Authority at the science-policy interface}

This section conveniently refers to these "what to do politically about the science' interactions in the Arctic Council as being a 'science-policy interface.' However, this handy term has several general shortcomings that the reader should keep in mind before we proceed with the Arctic case.

For one, this tidy division builds on a notion of how roles are played that is often challenged in scholarly writings but is widespread in popular perception: that scientists play a political role (when they choose to) by always 'speaking truth to power', and their 'statements' either being picked up (or ignored) by strategically selective politicians (Lidskog and Sundqvist, 2015). In this perspective, experts involved in international activity are meant to constitute a unified 'epistemic community' and act as agents of knowledge diffusion or informational entrepreneurs, proactively disseminating internationally produced information (such as climate assessments) (Adler, 2005; Haas 1992, 2015; Cross, 2013). By contrast, Bernstein's (2001: 487) observation that scientific knowledge may be necessary, requested and supplied in processes 'shaped by politics rather than by science' probably gives more analytical purchase in most science-policy interactions.

Secondly, the idea of a science-policy interface also draws the line between science and politics much more distinctly than the division as it exists in practice, as many studies in the history and sociology of science have shown (see, for example, Barnes et al., 1996; Demeritt, 2001; Collins and Pinch, 1998; Latour, 1987; Shapin and Schaffer, 1985). This scholarship does not say that scientific findings are political or biased, but rather seeks to draw attention to how politics and knowledge production are in constant interplay. For example, the questions of deciding what disciplines or forms of enquiries get funded and to what degree is often subject to political interventions and debates. And there is no purely 'politics only' form of politics, either. Policy debates are often a complex mix of statements and arguments about what we know (science, facts) and what we should value (Dessler and Parson, 2010). This mix of statements is not an accident. Politicians and policy actors prefer to have science on their side, as a way of giving their arguments the added ballast of impartiality (Dessler and Parson, 2010: 56).

The closer one gets to decision-making levels the more extensively reworked and oriented towards policy does the 'science' side of the science-policy interface become. Most of the science presented for consideration in cross-border governance has been vetted or selected beforehand. Higher-level diplomats and politicians do not face piles of unfiltered research or the most recent academic journal articles (nor the academics that produced them). Rather, compilations of research presented with carefully articulated degrees of certainty about change expected and 
measures that could work are presented. The policy implications of Arctic Council scientific assessment work in the Arctic are often first cleared politically with WG Heads of Delegation (HoDs) to the various Arctic Council WGs interfacing first with their national SAO (see Spence, 2016, for a description of this activity within the AMAP WG). Additionally, we also see commissioned work from independent consultants that includes both the knowledge baseline and policy recommendations, primarily in issue areas closer to technical/governance issues rather than natural processes or environmental change. Examples include reports from the international engineering and management consultancy Det Norske Veritas (DNV) on heavy fuels (DNV, 2011) and specially designated sea areas (DNV, 2013).

This chapter focuses on the 'downstream' where expert knowledge meets political consideration at the international level of Arctic governance. One may expect to find considerably different dynamics within the 'upstream' of the WGs - and also variation across them. For example, one could anticipate that indigenous peoples' organisations are likely to be a strong voice within the Sustainable Development WG, with its emphasis on the 'people politics' of the Arctic Council. The dynamics in the Barents cooperation and certainly at various local and national levels surely possess their own 'local' character. And certainly, the dynamics of the national downstream science-policy interface are even more variable (see Wilson Rowe, 2013c for an example of the reception of Arctic climate science in Russia).

To get at some of the dynamics of authority at the science-policy interface downstream (when knowledge is deployed for policy consideration), I have gathered moments of active discussion/contestation of the function and place of science in the Arctic Council. Arctic Council minutes from the last ten years were analysed for active moments when the position and relevance of science work were debated at high-political meetings. Key themes coming from this analysis centre around the following questions. Who speaks for the Council? When does science become policy - and where do the policy conclusions get vetted? When is there enough science - or even too much - for political action?

\section{Who speaks for the Council?}

One window for understanding the science-policy interface at the Arctic Council is to follow discussions over who is meant to speak on behalf of the Council - or represent an Arctic environmental problem - on the global stage. These debates also tie into the broader question of the relationship between the frequently semi-autonomous WGs (with long 
institutional memory on Arctic issues) and the regularly shifting diplomatic and political representatives of states.

During the 2015-2017 US chairmanship period, the question of the Arctic Council's component parts' external relations to other governance bodies was raised in several guises. On one general discussion of communications and 'who speaks for the AC [Arctic Council]', the minutes from one SAO meeting indicate that there was 'no agreement':

Most delegates expressed the view that Working Group Chairs and Heads of Delegations are the primary spokespersons for Working Group activities and may speak on factual/technical matters relating to the work of the Arctic Council, but that they should not speak publicly on policy matters on behalf of the Arctic Council writ large. Some delegates prefered $[$ sic] that Working Group Chairs, rather than secretariats, speak publicly'.

(Arctic Council Secretariat, 2015c: 6)

This last point is interesting, in that WG chairs go through periodic national-level selection processes in which political voices can be heard, whereas the secretariats operate at a more arm's-length distance from political selection processes and often have longer-term employees.

In a more specific context, this issue of representation and voice was revisited in connection to global climate politics. In the final report of an SAO meeting held in Anchorage in 2015 (Arctic Council Secretariat, 2015c), the visibility of the Arctic Council at the landmark UNFCCC Conference of Parties (COP) 21 was discussed. The discussion was triggered by a WG (AMAP) stating that they wished to participate in a public event at COP21 organised by the Nordic Council of Ministers. However, 'several delegates thought it would not be appropriate to have a single Arctic Council working group participate in an event of this kind' organised by an outside international organisation (Arctic Council Secretariat, 2015c: 5). The solution landed upon, after some discussion, was that AMAP would not participate publicly at COP21, but that Iceland would use some of its own booth space to display Arctic Council publications in Paris.

Similar issues had also been brought up during the 2009-2011 Danish chairmanship and, once again, in connection to an AMAP effort. It had made some films that powerfully communicated the environmental challenges covered in a recent environmental assessment. Concern was expressed by some SAOs about AMAP having made the films, and there was a discussion regarding the need for 'more transparency if such films were to be produced in the future and also as to the geographical areas/ regions shown in the films: films should represent all Artic states and the full spectrum of affected Arctic ecosystems and priority should be given to all indigenous peoples, not just one or two'. Interestingly, however, the indigenous representatives pushed back, arguing that 'they believed 
the film on the human dimension captured the conditions of indigenous people very well and expressed its concerns as to the issue of how to adapt to climate change' (Arctic Council, 2011a: 4).

As will be discussed below, speaking/objecting on behalf of indigenous residents of the Arctic can lend a certain moral weight to the argument. In this case, however, an important feature of claiming authority in the Arctic Council made itself plain - indigenous peoples were there to speak on their own behalf, thereby removing the exclusive privilege of state representatives to speak on behalf of the 'people' within their borders.

\section{When does science become policy?}

Working groups lay out their plans for assessment and other scientific work, often early in a chairmanship period, for approval and comment. State representatives' commentary on the science tends to be focused on avoiding overlap (trying to get WGs to coordinate more), avoiding duplication and committing resources and data. It is important to keep in mind that states can also withhold resources on topics that they object to for any reason, although this occurs rarely. One example was that the USA was not positively disposed towards a proposed study comparing marine management practices in the Arctic. The reason was perceived duplication of other efforts, and the US representative consequently declared that it would not appoint a chapter author, but would instead submit an existing paper on the topic to the work (PAME, 2007: 4). On the whole, there is often little political-level comment on the planning stages of the WGs' plans or on the specific scientific findings and judgements - at least not reflected in the formal minutes (for a discussion of limitations involved in this source of data, see Introduction).

This dynamic, however, may be different depending on the topic of the assessment, and as the assessment concludes and efforts to formulate policy recommendations are made. The question of how and in what ways Arctic Council-based assessment knowledge was to be vetted at the national level became, for example, an acute issue for the 2007 OGA. Oil and gas production is, of course, a highly technical and economically strategic issue area around which to attempt an international cooperative assessment. The OGA was first presented in a finalised form to the SAOs in 2007 in northern Norway, and the SAO congratulated the authors and also noted that the report was still confidential at that stage.

When the AMAP chair announced plans to release the report at the Arctic Frontiers conference in Tromsø, and then at two regional conferences in Russia and Alaska, a discussion ensued about the difference between the scientific findings and the recommendations in the 'overview report' compiled for policy and public circulation. More 
specifically, 'clarity was sought as to whether the recommendations in the Overview Report are intended to be scientific or policy recommendations. If the latter, further clarity was sought on Arctic Council process to deal with policy recommendations from/approved within a Working Group and what the SAOs [sic] role to respond to the WG recommendations should be' (Arctic Council, 2007b: 9-10). In this field of high socio-economic relevance, it seems that some SAOs felt that the policy recommendations made by the WG were too prescriptive, or had somehow overstepped the mandate of normal procedure and division of labour between expert and political actors in the Arctic Council.

This observation sparked a discussion of how and when the political levels should intervene in shaping the recommendations or dissemination of WG outputs. Then AMAP sought to clarify its

understanding that the scientists prepare the scientific assessment and write the scientific conclusions and recommendations. The key findings and policy recommendations in the Overview Report were based on the science recommendations in the scientific assessment and negotiated among the AMAP working group heads of delegation with extensive national review.

The minutes further note that a participant argued that 'It has not been the policy for SAOs to alter Working Group reports. The precedent is for the SAOs to receive the work of the working group and recommend elements to bring forward in the SAOs report' (Arctic Council, 2007b: 9-10)

This standing procedure to which the unknown speaker had referred received support from 'most SAOs', and the chair further reiterated that the SAOs' role was to receive the recommendations. Other SAOs felt that the OGA contained statements that if intended as policy recommendations, [suggested that] the national review had been insufficient ... that a process for approval of the policy portion of the Assessment within governments was needed' (Artic Council, 2007b: 10). The SAOs agreed to finish their review of the policy portion by mid-January and that the policy recommendations and executive summary could only be released if comments from governments were addressed prior to the planned launch at the Arctic Frontiers conference (Arctic Council, 2007b: 11). At a later meeting, however, the official launch of the OGA was designated as a task of the SAOs (Arctic Council, 2007a).

In releasing the Snow, Water, Ice and Permafrost in the Arctic (SWIPA) assessment in 2010, and perhaps based on the troublesome experience of bringing the OGA to completion, AMAP raised the topic again of how policy recommendations should be developed. The following procedure was established: 
AMAP confirmed that AMAP HoDs would develop policy recommendations based on the science report and that these would be included in the summary report ... SAOs stressed that, with respect to the policy recommendations, it is the responsibility of AMAP HoDs to interact closely with their SAOs so that they are more comfortable with the report and its recommendations when it is delivered to SAOs.

Interestingly, however, SAOs sought to bring the natural-science-based SWIPA assessment into close conversation with the Arctic Council, asking for it to be seen as an Arctic Council report. It was noted by AMAP that it does not normally place an Arctic Council logo on sciencebased reports, but it requested SAO guidance on the topic. The SAOs nonetheless encouraged AMAP to finish the report early enough to allow for 'national consultations' before the next meeting (Arctic Council, 2010a: 6).

Likewise, at different political moments and perhaps involving different diplomats, state representatives have sought to blur the distinction between science and policy - or to be able at least to celebrate scientific cooperation as a political success as well. At an SAO meeting held in Whitehorse in 2015, at a low point in Russia's relations with the West (see Chapter 2 for a discussion of post-2014 Arctic diplomacy) and in response to the presentation of the Arctic Guide on Oil Spill Response in Ice and Snow from EPPR, Russia noted as a positive that the report is both 'technical and political' (Arctic Council Secretariat, 2015a: 18). At this preministerial SAO meeting in Whitehorse, Russia also paid extra attention to AMAP's work and opened a discussion about how AMAP results could be made more accessible to the broader public and politicians (Arctic Council Secretariat, 2015a: 13). The point here is that changing political landscapes more broadly - as well as the regularly shifting diplomats sent by states - probably contribute to the ongoing dynamism of the sciencepolicy interface of the Arctic Council, even twenty years in.

Furthermore, it is important to reiterate that the science-policy interface at the Arctic Council does not seem to be about political actors seeking to control the scientific findings or assessment conclusions themselves. Undergirding this observation is a discussion about two scientific articles produced under ACAP - in which SAOs make it clear they have no intention of seeking to review or judge the validity of scientific findings. ACAP WG raised the question of publications for peerreviewed journals that had come of the work included in the ACAP working plan, but that did not have or require ACAP or Arctic Council logos or branding. Delegates are reported to have:

agreed that scientific or technical reports that do not contain policy recommendations and that are complete and ready to be released in peer-reviewed journals (or otherwise) could be released when they are 


\section{Arctic governance}

ready. WGs should not feel compelled to delay publication in order to wait for a Ministerial meeting. Scientific/technical publications that do not contain policy recommendations do not require SAO approval ... However, if a product responds directly to a directive from Ministerial Declaration or contains policy recommendations, it should be saved for release at the next appropriate Ministerial meeting ... In addition, WG chairs are required to bring any product containing policy recommendations before SAOs for review.

(Arctic Council Secretariat, 2015c: 9)

Political concern tends, instead, to be much more closely tied to how results are communicated (by whom and when and after what kind of process) and, especially, to how policy recommendations are formulated and communicated (and by whom).

\section{When do you know enough?}

It is also important to keep in mind that science or expertise is probably not always considered useful by policy field participants in global governance - or not beyond a certain point. For example, in international negotiations around climate change mitigation, diplomats reported frustration and irritation over negotiation participants who become too hung up on certain technical nuances when the political drift of the negotiations had clearly moved forward regardless (Wilson Rowe, 2015; see Seabrooke and Henriksen, 2017, for a broader discussion).

The Arctic Council archival documents only give us one example of this kind of limit-drawing about a sufficient evidence basis - at least until political actions start to be taken to 'catch up'. The point was made by the US chairmanship team at an early SAO meeting during American leadership. A paper introduced by the chairmanship made the following point about the sheer number of regulatory and knowledge-based recommendations that have been made: 'there have been - by one account - some 238 recommendations made by the Arctic Council on oil and gas activities' (US Chairmanship of the Arctic Council, 2016a: 2-3 (emphasis in original)). This was celebrated in the report as an indication that the Council had effectively evolved to 'address real world changes in the realm of oil and gas. However, the current assemblage of working groups, task forces, expert groups and bodies outside the Council (e.g., [The Arctic Offshore Regulators Forum]) that all have involvement in oil and gas issues presents a coordination challenge to the Council' (3). In other words, the Council had produced a multitude of well-founded, well-researched recommendations on oil and gas, but the sheer number of recommendations and actors involved in producing them limited their practical usage in national-level politics, where decisions about oil and gas are made. 
This brings us back to the point we discussed above about the science policy interface - science may be called upon but be neither decisive nor sufficient as a basis for policymaking in some processes. Before discussing what these various moments of debate over the science-policy interface tell us about the civic epistemology of the Arctic Council, we turn first to a fundamentally important set of governance actors in the Arctic with a substantive claim to authority in the Arctic context - the Permanent Participants representing the indigenous peoples of the region. We then combine these two interfaces to think systematically through what they in combination can tell us about authority in Arctic governance.

\section{Authority at the Peoples-State interface}

Several of the organisations taking part as Permanent Participants at the Arctic Council grew out of the social movements around indigenous peoples and their land that emerged in the 1960s and 1970s. Major new economic opportunities bringing further incursions into indigenous lands, such as Alaska's oil wealth and the building of the Trans-Alaska Pipeline System, or seeking to harness the hydroelectric potential of James Bay in northern Quebec, catalysed these movements and had triggered formal negotiation processes between indigenous peoples and the State, such as the Alaska Native Claims Settlement Agreement of 1971 or the James Bay and Northern Quebec Agreement of 1975.

However contested or incomplete these agreements were seen to be at the time, or have come to be seen since, the process of negotiating them forged experienced, powerful, indigenous collective and individual voices calling for justice and equality (Abele and Rodon, 2009). The ICC was pushed forward by a complex set of North American domestic and international factors, and quickly became an important actor within a burgeoning indigenous internationalism taking place in international organisations, such as the United Nations (Smith and Wilson, 2009; Shadian, 2014, 2017). Within the Nordic Arctic, the Saami had for decades become increasingly organised because of internal push factors and also international processes, such as the negotiation of the International Labour Organization's resolution on indigenous peoples (Kuokkanen, 2009).

The genesis of Russian Arctic indigenous peoples' political mobilisation was somewhat different. In the Soviet Arctic, the indigenous peoples of the North, formerly known as inorodtsy (aliens) under the tsarist empire, were renamed the 'small-numbered peoples of the North'. Although these peoples were not considered nations, the smallnumbered peoples of the Russian North also underwent the Soviet efforts to recruit minority ethnicity/indigenous intelligentsia from the 1930s and onwards (Krupnik, 1993; Slezkine, 1994; Vakhtin, 1994). 
This intelligentsia was meant to bridge the gap between indigenous and Soviet cultures (Haruchi, 2002: 86). Simultaneously, there were focused and often brutal efforts to resettle nomadic indigenous groups, primarily reindeer-herding peoples, into villages and to transform nomadism as a way of life into nomadism as a form of Sovietised collective production (Pika, 1999; Vitebsky, 2005).

The end of the Soviet Union witnessed the increased political activity of this indigenous political elite (Haruchi, 2002). With the introduction of perestroika and an accompanying reduction in censorship, the issues facing indigenous Arctic Soviet peoples came to be discussed publicly (Slezkine, 1994). In 1989, a three-day congress of 250 indigenous representatives met to debate and to select representatives for an AllUnion Congress of Native Peoples of the North. This was a product of Gorbachev's perestroika and also a response to increasing international pressure (Kaplin, 2002; Murashko, 2002). This congress gradually evolved into RAIPON, in part thanks to practical and financial support from Canadian actors (Wilson, 2007a).

So, how were these organisations representing indigenous peoples of the Arctic to participate in the rapidly expanding cross-border politics of the post-Cold War Arctic? Initially, it was proposed that perhaps the indigenous peoples' organisations should enjoy the same privileges awarded to states. This was seen by many state representatives as a challenging proposition. The USA, for example, partially resisted establishing the Arctic Council, as it raised too pointedly the issue of how indigenous peoples would participate in the proposed new format. There was limited specific concern for the Arctic context, but a broader question of how the inclusion of indigenous peoples as equals could bring a new set of challenges to Alaskan politics and set a diplomatic precedent challenging State authority and existing practices for other international fora. Neither had Norway or Denmark been immediately enthusiastic (English, 2013: 188, 186).

An experienced diplomat and civil servant long engaged with northern questions, Walter Slipchenko, proposed as early as 1992 that indigenous peoples would need to be represented as something more than 'observers' alongside other NGOs, and introduced the category of 'Permanent Participant' for Arctic cross-border settings, which would grant access and participation at all levels of discussion (English, 2013: 167, 181; Shadian, 2014). The United States in turn insisted that the number of Permanent Participants be expanded from the original three (Saami Council, RAIPON, ICC) to also include three new organisations founded to participate in the Arctic Council - the Arctic Athabaskan Council (USA/Canada), the Gwich'in Council International (USA/Canada), and the Aleut International Association (USA/Russia).

Below, I explore three key themes that can be pulled out from the interventions made by these long established and more newly minted 
Permanent Participants in high-level Arctic Council meetings in the past ten years, as reflected in minutes and reports. Key topics include the importance of (and challenges to) Permanent Participant participation in the increasing scope of Arctic Council activities, speaking for the peopled Arctic and calling states to account.

\section{Strong political representation in diplomacy, challenged in agenda-setting in the upstream}

Within the Arctic Council indigenous participation varies, and this variable participation is frequently linked to problems of capacity. The Indigenous Peoples' Secretariat was established to support the participation of Permanent Participants in Arctic Council work, and how this secretariat is funded and functions has been a frequent focal point for capacity questions. For example, during the Norwegian chairmanship, the Permanent Participants submitted a document clarifying and reminding states about Permanent Participants' role in the leadership of the Indigenous Peoples Secretariat, while underlining that the indigenous leadership role does not dilute the responsibility of the states to continue funding the secretariat (Arctic Council/Indigenous Peoples Secretariat, 2008). In a broader sense, Jim Gamble, Executive Director of the Aleut International Association, notes that every Ministerial Declaration since Ottawa has mentioned the importance of states supporting Permanent Participant capacity. He argues that this testifies to the broadly recognised value that the Permanent Participants bring to the work of the Council and to the unresolved problem of how best to support these small organisations faced with an ever-expanding portfolio of Arctic governance issues (Gamble, 2016).

Across the board, however, Permanent Participant representatives already do participate more consistently than observer states in the various facets of the Arctic Council's work (Knecht, 2017: 9), although at levels less than those of state representatives. Permanent Participants are nearly always present at ministerial meetings and SAO meetings, but with decreased participation in WG meetings (41 per cent average participation) and task force meetings (34.5 per cent) (Knecht, 2017: 8). Coote notes that indigenous peoples' organisations also participate in the upstream of Arctic Council work that takes place in the WGs, although may struggle to set the agenda there because of capacity limitations (2016).

On a related note, it is therefore unsurprising that one topic of debate that sparked 'intensive discussion' was the role of Permanent Participants in conceiving projects. Permanent Participants argued that greater transparency was needed as to whether the indigenous peoples' representatives had been consulted, and whether the inclusion of traditional knowledge had been considered, in early phases of project development. This 
included making a checklist point on indigenous participation a requirement for early phases of Arctic Council projects and having this consideration (or lack thereof) made visible in the newly established project overview database (the Amarok project tracking document) (Arctic Council, 2015c: 8). Seeking to enshrine consideration of indigenous knowledge, perspectives and participation in the project-planning process was one way of ensuring that these issues were considered, even if the Permanent Participants themselves could not be at each meeting to place them on the agenda.

\section{Speaking for the living Arctic}

There are two main areas of emphasis that we can extract from the formal diplomatic statements and recorded interventions of the Permanent Participants at the Arctic Council. First, as we saw in Chapter 2, indigenous representatives weighed in heavily on the question of the extent to which Russia's problems with other Arctic countries after 2014 should interfere with or overshadow progress in Arctic cooperation. Permanent Participants' interventions stated that the cooperative cross-border nature of the Arctic region must be preserved, even considering conflict between Arctic countries outside the region.

Another important discursive intervention is insistence on political attention to the 'people' politics that can be addressed at the inter-state level, including questions of economic development. A sampling of statements made by indigenous representatives at the 2011 Nuuk ministerial meeting serves to illustrate this point. As we saw in Chapter 2, the Greenlandic statement argued for the importance of both pursuing economic opportunities and protecting the environment: 'the Arctic is not just about polar bears and ice. What is often missing from the discussion is the human aspect of the Arctic and the conditions in which we live' (author's translation from Danish, Kleist, 2011: 3). Sergey Kharuchi's statement for RAIPON also highlights the living, human aspect of the Arctic (RAIPON, 2011). A statement from the Saami Council at the same ministerial session raises a key socio-political question of international relevance, given how many of the extractive industries operate in more than one country, calling for the importance of benefit-sharing in extractive industries (Saami Council, 2011).

\section{Calling states to account}

Indigenous peoples' organisations also use the Arctic Council setting to hold state representatives to account in facilitating the basis of 
their participation. This includes attention to the Arctic Council's efficiency and concern over duplicative structures. For example, the Arctic Athabaskan Council pushed hard in 2007 for the WG structure to be revisited and streamlined, calling for the Norwegian chairmanship to devote some serious attention to the question of efficiency (Arctic Athabaskan Council, 2007). For organisations with small staffs, ensuring that the main action starts and finishes in the SAO and ministerial meetings has been important.

Permanent Participants also play a role in on-the-record naming and shaming, something we do not see state representatives doing. Given that public calling-out is unusual in this context, it becomes a powerful way of calling to account. At the Kiruna ministerial meeting, Chief Michael Stickman, once again, as at the Nuuk ministerial session (Arctic Athabaskan Council, 2011), criticises the lack of immediate action on black carbon and the continuous establishment of task forces, rather than a concrete action plan. He specifically asks Prime Minister Lavrov, with the 'greatest respect', to explain why this is the case, as it is Russia who has opposed action on black carbon (Arctic Athabaskan Council, 2013). There are few other settings in the world where a native chief can call the Minister of Foreign Affairs to account.

Likewise, the Swedish Saami representative used the home-turf ministerial meeting to present a negative picture of indigenous rights in Sweden:

here in the Giron area, industrial development - in particular
mining - poses a tremendous challenge to the local Saami reindeer
herding people. In our delegation, we have local reindeer herders with
us that can witness to the fact that corporate responsibility can be a
two-edged sword. The Swedish government says that we expect the
mining industry to behave responsibly when operating in the Saami
areas. But at the same time, the mining company says we have to follow
Swedish law. Here in the Giron area, corporate responsibility equals no
responsibility.

(Saami Council, 2013)

RAIPON seems to use sessions of the Arctic Council to make points that many other indigenous organisations would probably have taken care of domestically. For example, in Copenhagen at the 2009 SAO meeting under the Norwegian chairmanship, RAIPON noted that Russia had yet to contribute any data to the flagship ministerial deliverable, the Arctic Marine Shipping Assessment (Arctic Council, 2009a: 2). At a 2010 SAO meeting in Tórshavn, RAIPON took the opportunity to request that they be more involved in Russian governmental work on Arctic issues, for example in ACAP (Arctic Council, 2010b: 11). The centralisation of authority from the regions to Moscow and from multiple branches of government and civil society into the executive in Russia, discussed 
in the previous chapter, may make the Arctic Council one of the more important meeting spaces for a Russian organisation to meet Russian authorities.

To take an Arctic example of a statement made to a broad audience, including the Arctic Council member states, 'A circumpolar Inuit declaration on sovereignty in the Arctic' made assertions about the peoplehood of the circumpolar Inuit, to mitigate the sovereign claims of states (see Beyers, 2014 for an extended discussion):

The conduct of international relations in the Arctic and the resolution of international disputes in the Arctic are not the sole preserve of Arctic states or other states; they are also within the purview of the Arctic's indigenous peoples. The development of international institutions in the Arctic, such as multi-level governance systems and indigenous peoples' organizations, must transcend Arctic states' agendas on sovereignty and sovereign rights and the traditional monopoly claimed by states in the area of foreign affairs. Issues of sovereignty and sovereign rights in the Arctic have become inextricably linked to issues of self-determination in the Arctic. Inuit and Arctic states must, therefore, work together closely and constructively to chart the future of the Arctic.

(ICC, 2015a)

Here, we see an interesting feature of the 'civic epistemology' of the Arctic, to which we now turn. In the Arctic Council, states cannot derive authority by speaking on behalf of the populations of their state. Rather they have to interface with and cooperate (or fail to do so at their own expense) with representatives of a 'third space diplomacy' (Beier, 2009) the Permanent Participants' organisations who are both inside multiple states and outside them at the same time.

\section{A civic epistemology of Arctic governance?}

In this concluding section of the chapter, we return to the 'civic epistemology' rubric developed by Jasanoff to point to what may be some enduring features of how authority is negotiated and shaped in Arctic governance. My aim in utilising the civic-epistemology framework is not to deliver the final word on authority in Arctic governance, but rather to bring the observations about the performance and contestation of Arctic power relations by non-state actors into systematic and comparative focus.

Utilising a more dynamic, present-oriented framework is also meant to deliver a supplement to 'field-genealogy'-driven forms of analysis as a historical unpacking of governance fields. A historical approach, while 
bringing to light important origins of why certain actors, framings or resources brought to a policy field matter more for shaping outcomes, may also reify contestation over authority as a one-time (if uphill) battle and fail to notice that authority remains constantly contested and renegotiated. As we saw above, natural-science and scientific actors have long been enshrined as central actors in Arctic governance, yet when and how they are meant to intercede/interface with the political and diplomatic levels of the Arctic Council remained a debated topic, even twenty years in. Furthermore, given the complexity and interconnectedness of the overlapping policy fields that make up Arctic cross-border governance (and the multitude of actors with their own histories of political development actively shaping these fields), an empirically rigorous genealogy that takes all of this overlap and complexity into account may be challenging to carry out.

In her civic-epistemology framework, Jasanoff compared attitudes and political processes around biotechnology in three countries that one would not necessarily expect to have radically different approaches to questions of what counts for authority. Jasanoff (2005) employed six indicators to unpack expectations about the use of expert knowledge at the national level in the UK, the USA and Germany. The findings of this chapter about tussles around authority science-policy and peoplestate interfaces at the high-level political meetings of the Arctic Council speak to four of the indicators identified by Jasanoff (slightly adapted for use here):

(1) Trust. How do we discern credibility of statements?

(2) Visibility of expert bodies. Behind the scenes? At the forefront of public debates?

(3) Objectivity. What is the balance between scientifically valid, numerical inputs and other inputs such as social and political concerns in the outcome? How are outcomes negotiated?

(4) Recognition/success. What makes a participant able to secure deference for or support of their claim?

In terms of trust, the debates around science-based interventions and Permanent Participant interventions seem to suggest little attention devoted to issues of trust in efforts to gain authority. There are no accusations of 'bad science' or work poorly carried out, or suggestions that Permanent Participants or others are failing to represent their own stated interests or constituencies. The SAOs did indeed take the WGs to task several times, especially AMAP, for what they considered to be a potential overstep of procedures, such as having science findings that seemed to them too much like policy findings, and seeking to take a public stage too frequently or with innovative forms of communication, such as film. 
In terms of Permanent Participants' relationship to the states, we see that states are not automatically trusted to do what they have promised or to do what is best for the Arctic based on the science gathered and used as a basis for policymaking. There is never a reason given, however, for why states would not do this, and it is a likely assumption to make that it has more to do with the broad political and economic costs of action for states in, say, climate mitigation, than with a distrust towards the actual representatives of these states. Rather, this ties into a universal issue of politics on long-term environmental problems that outstrip election cycles. Perhaps because the Permanent Participants' diplomatic stakes are more squarely centred on the Arctic, they are more able and willing to challenge states directly on key issues, as in the case of Chief Stickman's comments to Russia on their perceived foot-dragging with regard to black carbon.

The contentious issues relate, rather, to the visibility of expert bodies outside the Arctic Council in other global fora. Experts and WG representatives are highly visible at the meetings and associated events of the Arctic Council itself. The tricky question is about their global intersection with other international organisations and professional networks. Monitoring existent and curtailing further expansion in the independent diplomatic networks of the WGs was a pursuit encouraged by both SAOs and Permanent Participants during the American chairmanship. In other words, while science inputs are essential for governing the Arctic, the political representatives operate with a strong sense that scientists should not speak for the Arctic, particularly in connection to global audiences.

Ensuring that the wide network of experts surrounding the Arctic Council is first streamlined through the political level may be a particularly important issue for the Permanent Participants in seeking to exercise their special position as the original peoples of the Arctic. Because of their capacity challenges in participating in agenda-setting work within the Arctic Council's WGs, Permanent Participant representation in WGs is nearly half their level of participation in the higher-level political meetings. It thus becomes especially important that the main action, core messages and course-setting decisions are made in those meeting settings. All this ties in well with the characterisation of experts as being appreciated, and 'on tap' but not 'on top' in the driving forward of policymaking or identification of policy consequences (Barnes et al., 1996). In sum, when speaking on behalf of the region to other political settings, Permanent Participants and states seem to be in agreement about retaining that global public voice for themselves.

When it comes to objectivity, at the high-level political meetings analysed here, objectivity was less of a concern. Because of the seemingly high levels of trust in the quality of the outputs of WG activity, 
participants at the meetings were not engaging extensively in issues relating to the balance between natural science and socio-political knowledge, or relating to the balance between quantitative or qualitative inputs. This may be because the mandate at these meetings is to agree on what can be said politically about the evidence basis, rather than to redo the assessment work of the various expert groupings that produced the report. Furthermore, the inclusion of traditional ecological knowledge/traditional knowledge in some of the Arctic Council's work, however incompletely or sporadically, probably introduces a grain of humility about different forms of knowledge and ways of knowing, thus limiting the utility of attempting to raise one form of one source of knowledge high above another. It seems that it is clear to the participants that what is at stake at the higher-level Arctic Council gatherings is not the empir$\mathrm{ical} / \mathrm{scientific} \mathrm{basis} \mathrm{or} \mathrm{validity} \mathrm{of} \mathrm{the} \mathrm{problems} \mathrm{presented,} \mathrm{but} \mathrm{rather} \mathrm{what}$ to do about them and how to frame them for broader global and national 'home' audiences.

In sum, what makes an authority? Progress in the Arctic Council is highly reliant on agenda-setting and evidence-gathering done by the WGs, and their contributions are trusted and actively used by other policy field participants. However, state representatives and the Permanent Participants all actively engage in efforts to secure their own authoritative positions, particularly vis-à-vis the semi-independent WGs with longstanding secretariats and staff, and markedly less so vis-à-vis one another as explicitly political actors. This occurs primarily along the dimension of who speaks on behalf of the Arctic Council, and is evident especially in contestation over who will address non-Arctic settings and who will be able to draft and disseminate to a global audience evidencebased policy conclusions. Both states and Permanent Participants claim an (overlapping) authority rooted in geography, statehood and peoplehood to speak on behalf of the Arctic and its peoples, extending beyond an expertise-based performance of authority that science actors may bring. In other words, while the Arctic policy field requires scientific input, the policy field has developed in such a way that the most successful performance of authority remains explicitly political, rooted in the logics of sovereignty and statehood. 